\title{
Similar Acid Stimulatory Potencies of Synthetic Human Big and Little Gastrins in Man
}

\author{
V. E. Eysselein, V. Maxwell, T. Reedy, \\ E. Wünsch, and J. H. Walsh \\ Center for Ulcer Research and Education, Veterans \\ Administration Center Wadsworth, Los Angeles, \\ California 90073
}

bstract. A newly synthesized human big gastrin (G34) that was prepared according to the revised structure and that contained $<3 \%$ oxidized methionine residues was compared with synthetic human little gastrin (G17) for acid-stimulating activity and clearance in human subjects. Prolonged infusions of each type of gastrin revealed that the time required to approach stable plasma concentrations was much longer for G34 than for G17. The time course of plasma gastrin concentration could be described by one-compartment models with half-lives of $44 \mathrm{~min}$ for G34 and $8 \mathrm{~min}$ for G17. After rapid intravenous infusion, G34 produced a much larger total acid response than did an equimolar dose of G17, and the responses were directly proportional to the integrated plasma gastrin increments. During the third hour of prolonged intravenous infusions of G34 and G17, the exogenous dosage of $\mathrm{G} 34$ required to produce the same blood concentration of gastrin was only one-fourth that of G17. Equivalent blood concentrations of G34 and G17 were associated with similar rates of acid secretion. These results suggest that G34 is more potent than has been thought, that it has an activity similar to that of G17 and that it must not be ignored in estimating total acid-stimulating activity of circulating gastrins. The measurement of total carboxyl-terminal immunoreactive gastrin can produce a good estimate of total acid-stimulating activity.

\section{Introduction}

It is well established that the two major forms of gastrin in blood and in gastrin-producing tissues are the 34-amino acid big gastrin (G34) ${ }^{1}$ and its carboxyl-terminal heptadecapeptide

Received for publication 27 December 1982 and in revised form 10 January 1984.

1. Abbreviations used in this paper: DU, duodenal ulcer; G17, little gastrin; G34, big gastrin.

The Journal of Clinical Investigation, Inc.

Volume 73, May 1984, 1284-1290 fragment, little gastrin (G17) (1). Biological activities and metabolic clearance rates of $\mathrm{G} 34$ and $\mathrm{G} 17$ have been studied previously in dogs (2) and in humans (3). The gastrins used for these studies were obtained by extraction and purification from a large human gastrinoma (4). It was concluded that G17 was approximately six times more potent than G34 as a circulating stimulant of gastric secretion. Because G17 was cleared from the circulation about six times faster than G34, the two peptides appeared to be equally potent when given by continuous intravenous infusion $(2,3)$. It was found that $G 34$ was the predominant form of gastrin in blood taken from fasting subjects, but that $\mathrm{G} 17$ and $\mathrm{G} 34$ were present in similar concentrations during stimulation by food $(5,6)$. From these studies it was concluded that G17 was the more important gastrin and that G34 played only a minor role in regulating gastric secretion by the circulating gastrins (7).

The amount of natural human G34 is quite limited, and further evaluation of the biological properties of G34 has depended upon synthesis of a peptide with identical structure. Studies with one preparation of synthetic human G34 indicated that it and G17 are equally potent stimulators of lower esophageal sphincter contraction (8). It was not known if there was a difference in organ responsiveness between esophagus and stomach. Further examination of this question was suspended when Dockray provided immunochemical evidence for an error in the sequence determinations of the amino-terminal portions of porcine (9) and of human (10) G34. The chemical basis for this difference was discovered at positions 7,8 , and 9 , where the sequence His-Pro-Ser reported initially should have been ProPro-His (1). This change has been confirmed by direct analysis of the porcine (11) and the human (12) complementary DNA sequence. The complete synthesis of human G34 according to the revised sequence was recently achieved, and the peptide obtained was shown to be pure by extensive chemical and chromatographic testing (13). This synthetic G34 preparation was used to reevaluate clearance rates and acid-stimulating activity.

\section{Methods}

\section{Subjects}

The study group consisted of six male control subjects (aged 32-61 yr, mean 49) who had no symptoms that suggested peptic ulcer disease, 
and six male patients with duodenal ulcer (DU) disease (aged 59-72 yr, mean 62). All the ulcer patients had inactive ulcer disease, were free of ulcer symptoms at the time of the study, and did not take histamine antagonists. No drug was taken during the $36 \mathrm{~h}$ before the study. All subjects gave full informed written consent, and the studies were approved by the Veterans Administration Wadsworth Research and Human Subject Protection Committees. G17 and G34 were administered under Investigation New Drug numbers 10,872 and 18,719, respectively, of the U. S. Food and Drug Administration.

\section{Peptides}

Synthetic human G17, purchased from Research Plus, (Denville, NJ) was dissolved in $0.15 \mathrm{M} \mathrm{NaCl}$ containing $0.25 \%$ human serum albumin at a concentration of $10 \mathrm{nmol} / \mathrm{ml}$ under sterile conditions. Vials containing $10 \mathrm{ml}$ of $\mathrm{G} 17$ were prepared under aseptic conditions by the University of California, Los Angeles Pharmacy and stored at $-70^{\circ} \mathrm{C}$.

Synthetic human big gastrin, which included the revised Pro-ProHis sequence in positions 7-9, was synthesized as previously described (13). Infusion solutions were prepared exactly as described for G17. The concentration of peptide obtained by weighing, by measurement of absorbance at $280 \mathrm{~nm}$, and by radioimmunoassay with antibody 1611 (14) or antibody 1296 (15) was within $10 \%$ of the predicted value. No correction was required for immunoreactivity, as the immunoreactivity of the G34 preparation varied between 0.9 and 1.0 , compared with 1.0 assigned to synthetic $\mathrm{G} 17$.

\section{Gastrin radioimmunoassay}

6-ml blood samples were collected in tubes containing EDTA $(10.5 \mathrm{mg} /$ tube) to which $0.2 \mathrm{ml}$ aprotinin (2,000 Krein inactivator units) (Trasylol; The Bayer Co., New York, NY) was added per 5-ml blood sample. Samples were refrigerated immediately and centrifuged within $30 \mathrm{~min}$, and the plasma was stored frozen until radioimmunoassay was performed. Gastrin was measured as previously described (14), and all measurements were done with antibody 1611 . This antibody has been characterized previously and was shown in the present study to react equally with G17 and G34 (15). In addition to blood samples, aliquots of actual infused solutions were taken from the tips of infusion tubes to confirm the accuracy of dilutions of gastrin standards.

\section{Intravenous infusions of synthetic G34 and G17}

Rapid intravenous injections. On separate days, six DU subjects received 50-pmol/kg doses of G34 and G17, each delivered over a 30-s period. Blood samples were taken over 15-s periods at intervals of 2.5-15 min for plasma gastrin radioimmunoassay. Gastric acid secretion was measured by titration of $\mathrm{pH} 7.0$ of samples obtained by aspiration through a nasogastric tube positioned in the most dependent part of the stomach, as previously described (3).

Stepwise intravenous infusions. Six DU patients were given consecutive intravenous infusions of $3,12.5,50,200$, and $800 \mathrm{pmol} / \mathrm{kg}$ per $\mathrm{h}$ G34 and G17 on separate days. Each dose was given for $30 \mathrm{~min}$. Gastric acid secretion was measured by intragastric titration (16), which was modified to use isotonic glucose rather than sodium chloride as the perfusion solution (17). Blood samples were obtained at 15-min intervals for gastrin measurements.

Continuous intravenous infusions. In six control and five DU subjects, G17 was infused intravenously at a dosage of $50 \mathrm{pmol} / \mathrm{kg}$ per h for 3 h. Gastric acid secretion was measured by aspiration during the infusion and for $1 \mathrm{~h}$ after it was stopped. Blood samples were taken over 15-s periods at 5-15-min intervals. In the same subjects, G34 was administered for $3 \mathrm{~h}$ at a dosage of $12.5 \mathrm{pmol} / \mathrm{kg}$ per $\mathrm{h}$. Acid secretion was measured during infusions and for $3 \mathrm{~h}$ after. Blood samples were taken during the same time periods.

In the five DU subjects, $\mathrm{G} 34$ was also given at a higher dosage, 50 pmol/kg per h for $3 \mathrm{~h}$, and the decay of plasma gastrin again was measured over the next $3 \mathrm{~h}$. During all these studies, gastric acid secretion was divided into 15 -min periods for measurement.

Finally, four DU subjects received $12.5 \mathrm{pmol} / \mathrm{kg}$ per h G34 infusions for $4 \mathrm{~h}$ to determine if longer infusion would lead to further increases in circulating G34.

\section{Gel filtration studies}

In four subjects, $1-\mathrm{ml}$ plasma samples taken during the third hour of continuous infusion of the higher dose of G34 were subjected to gel filtration analysis on $1 \times 100$-cm Sephadex G50 superfine columns as described previously (3).

\section{Calculations}

Disappearance rate constants and plasma half-lives of G34 and G17 were estimated for one- and two-compartment models, using weighted or unweighted least squares, by the computer program BMDP3R (18). The volume of distribution was calculated from the equation $V=d /$ $(c \cdot k)$ using the plateau principle of Goldstein et al. (19), where $V$ is volume of distribution in liters per kilogram, $d$ is dose in picomoles per kilogram per minute, $c$ is the plateau concentration during constant infusion in picomoles per liter, and $k$ is the rate constant determined from the one-compartment model. The clearance rate was calculated from the equation: clearance $=d / c$. Differences in acid stimulatory potencies of G34 and G17 were evaluated by parallel bioassay methods as described in detail by Elashoff (20). The relative potency calculated by this method was expressed in terms of G17, which was assigned a potency of 1.0. The potency of G34 would be significantly different from that of $\mathrm{G} 17$ at the $5 \%$ level if the confidence interval calculated for $\mathrm{G} 34$ did not include 1.0. Mean values are expressed \pm SE.

\section{Results}

Rapid intravenous injections. Plasma gastrin concentrations measured after rapid intravenous injections of G34 and G17 are shown in Fig. 1. One- and two-compartment models were fit to the decay curves. Somewhat better results were obtained with the one-compartment model, although it could be seen that the first points in the decay represented a small mixing compartment, as attempts to fit a two-compartment model failed in some subjects because of lack of convergence of the iteration procedure. When weights inversely proportional to the gastrin levels were used, the one-compartment model gave half-lives of $31 \pm 2 \mathrm{~min}$ for G34 and $5.2 \pm 0.7 \mathrm{~min}$ for G17. These results agree well with the values of 38 and 6.4 min determined previously for G34 and G17 (3).

When the plasma gastrin responses after the rapid intravenous infusion of both peptides were integrated over $180 \mathrm{~min}$, the integrated plasma gastrin response after G34, 4,318 pmol-min per liter, was 3.2 times greater than the integrated plasma gastrin response after G17, 1,376 pmol - min per liter. As shown in Fig. 2, the acid secretion rates paralleled the time course of the plasma gastrin concentrations. The total acid output in the 180 -min period after G34 infusion was 3.4 times greater than in the $180-\mathrm{min}$ period after G17 infusion. 


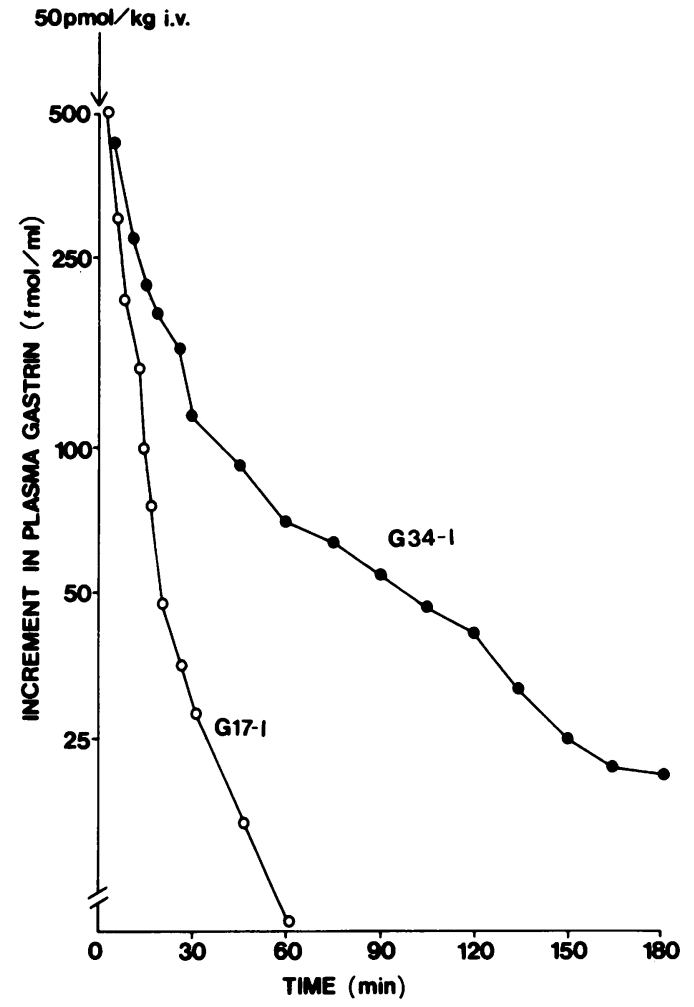

Figure 1. Disappearance of immunoreactive gastrin after rapid intravenous bolus infusion of $50 \mathrm{pmol} / \mathrm{kg}$ of G34 and G17 in six DU subjects. Points are mean values obtained after subtraction of basal values. G17 and G34 are in their nonsulfated forms.

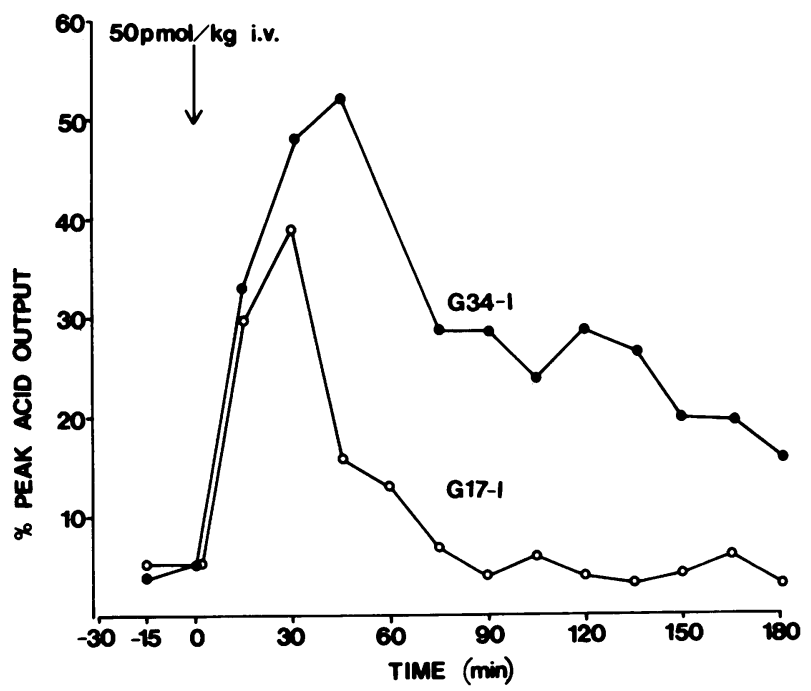

Figure 2. Gastric acid secretion measured at continuous 15-min intervals after rapid intravenous injection of $50 \mathrm{pmol} / \mathrm{kg} \mathrm{G} 34$ and G17 in the same six DU patients shown in Fig. 1. Peak acid output was taken as the response measured during infusion of $800 \mathrm{pmol} / \mathrm{kg}$ per $\mathrm{h}$ G17 on a separate occasion. G17 and G34 are in their nonsulfated forms.
Stepwise intravenous infusions. When consecutive 30-min infusions of quadrupling dosages of G34 and G17 were administered to five DU subjects, the plasma gastrin concentrations increased during each infusion period (Fig. 3). Because of the constant change in infusion rates during this study, it was impossible to estimate gastrin metabolic rates. The weighted mean gastrin concentrations (the mean value from the beginning and end of each infusion period plus twice the value at each midpoint, divided by four) were $2.4 \pm 0.1$ times higher during $G 34$ than during G17 infusions. The gastric acid secretion rates measured during these studies revealed quite similar acid responses to equimolar doses of G34 and G17 (Fig. 4). The potency of G34 estimated by plotting acid secretion rates vs. plasma gastrin concentrations was 0.57 compared with $\mathrm{G} 17$, but the confidence interval was $0.22-1.52$ and there was no significant difference in the potency estimates of G34 and G17.

Prolonged intravenous infusions of G34 and G17 in DU and control subjects. Since steady state conditions were not approached in the experiments described above, prolonged infusions of G34 and G17 were also given. Fig. 5 shows the results of 3-h infusions of $50 \mathrm{pmol} / \mathrm{kg}$ per h of G17 and of G34 in five DU subjects. During G34 infusion, plasma gastrin concentrations had reached $92 \%$ of calculated equilibrium concentrations after $180 \mathrm{~min}$. The time course of the plasma gastrin levels

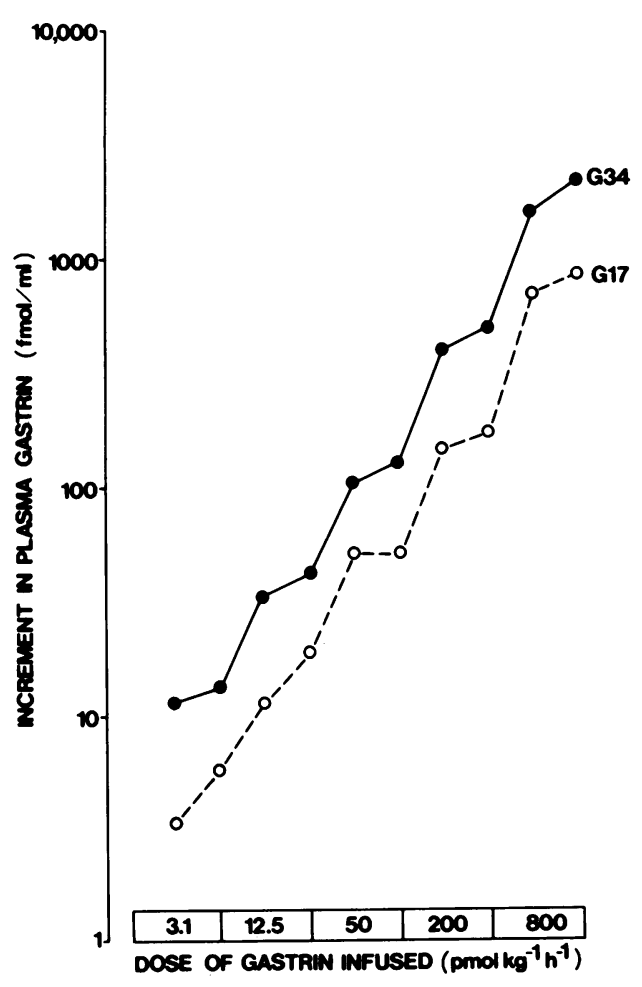

Figure 3. Plasma gastrin concentrations measured at 15-min intervals during continuous intravenous infusion of G34 and G17 at the indicated dosages for 30-min periods in six DU patients. 


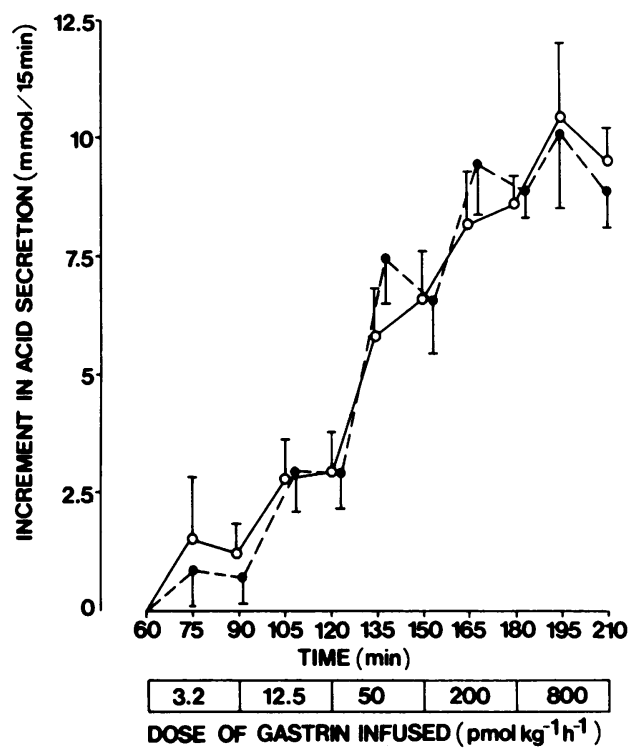

Figure 4. Increments in gastric acid secretion over basal levels in six DU patients during exogenous infusion of stepwise quadrupling doses of G34 (๑) and G17 (0) of 3.2-800 pmol/kg per $h$ for consecutive 30 -min periods. Acid secretion was measured by intragastric titration.

could be well described by a one-compartment model; there is no significant improvement in fit by adding a second compartment. The plasma half-life of G34 was $48 \pm 6 \mathrm{~min}$, the distribution volume was $30 \pm 3 \%$ body wt, and the clearance rate was $300 \mathrm{ml} / \mathrm{min}$. During infusion of G17, plasma gastrin reached a plateau after 20-30 min and showed a rapid decay by a onecompartment model with a plasma half-life of $8.7 \pm 3.3 \mathrm{~min}$, a distribution volume of $21 \pm 5 \%$ body wt, and a clearance rate of $1,367 \mathrm{ml} / \mathrm{min}$.

During the 3-h infusion of G34 in a dose of $50 \mathrm{pmol} / \mathrm{kg}$ per $h$, acid secretion rates increased steadily and reached a maximum after $90 \mathrm{~min}$ (Fig. 6). During infusion of G17 of the same dosage, acid secretion reached maximal values within $30 \mathrm{~min}$. Acid secretion rates during the continuous infusion of G34 were higher than during the infusion of G17. During the infusion of G34, acid output was as high as that obtained by stimulation by $\mathrm{G} 17$ in maximal dosage, $800 \mathrm{pmol} / \mathrm{kg}$ per h, on a separate day (there was an increment in acid secretion rates of $9.8 \mathrm{nmol} /$ $15 \mathrm{~min}$ ). Infusion of $12.5 \mathrm{pmol} / \mathrm{kg}$ per h G34 for $4 \mathrm{~h}$ to four DU subjects produced the same mean plasma gastrin concentration at the end of the fourth hour $(71 \mathrm{fmol} / \mathrm{ml})$ as at the end of the third hour $(72 \mathrm{fmol} / \mathrm{ml})$.

Plasma gastrin concentrations and acid secretion rates in response to submaximal doses of G34, $12.5 \mathrm{pmol} / \mathrm{kg}$ per $\mathrm{h}$, and $\mathrm{G} 17,50 \mathrm{pmol} / \mathrm{kg}$ per $\mathrm{h}$, were studied in five DU and six control subjects (Figs. 7 and 8). During the third hour of infusion, plasma gastrin concentrations and acid secretion rates reached similar values in both groups (mean increments of 47 vs. 50 pM and 5.9 vs. $6.1 \mathrm{mmol} / 15 \mathrm{~min}$ in the DU subjects and 46 vs. $58 \mathrm{pM}$ and $4.8 \mathrm{vs} .5 .1 \mathrm{mmol} / 15 \mathrm{~min}$ in the control subjects). Acid secretion rates after infusion of $\mathrm{G} 34$ reached $65 \%$ of maximal acid secretion in the DU and $69 \%$ in the control subjects. Therefore, on a molar basis, circulating G34 and G17 seemed to have similar acid-stimulating activity.

In the control subjects, the time course of the plasma gastrin levels after cessation of the infusion of $\mathrm{G} 34$ and G17 was measured for 3 and $1 \mathrm{~h}$, respectively. As in the DU subjects, the time course could be well described by a one-compartment model. Plasma half-lives of G34 and G17 (38.9 3.4 vs. $6.9 \pm 0.6$

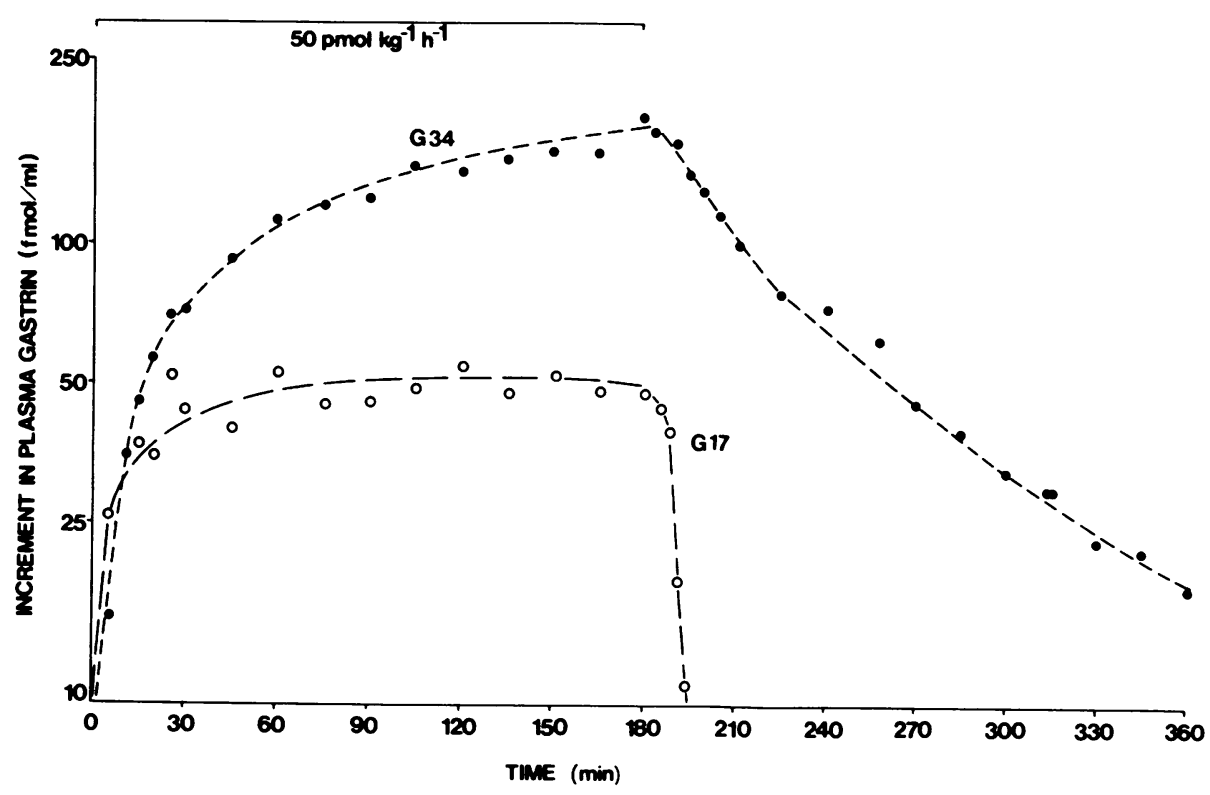

Figure 5. Plasma gastrin concentrations during and after 3-h intravenous infusion of G34 or G17 at a dosage of 50 $\mathrm{pmol} / \mathrm{kg}$ per $\mathrm{h}$ in five DU subjects. 


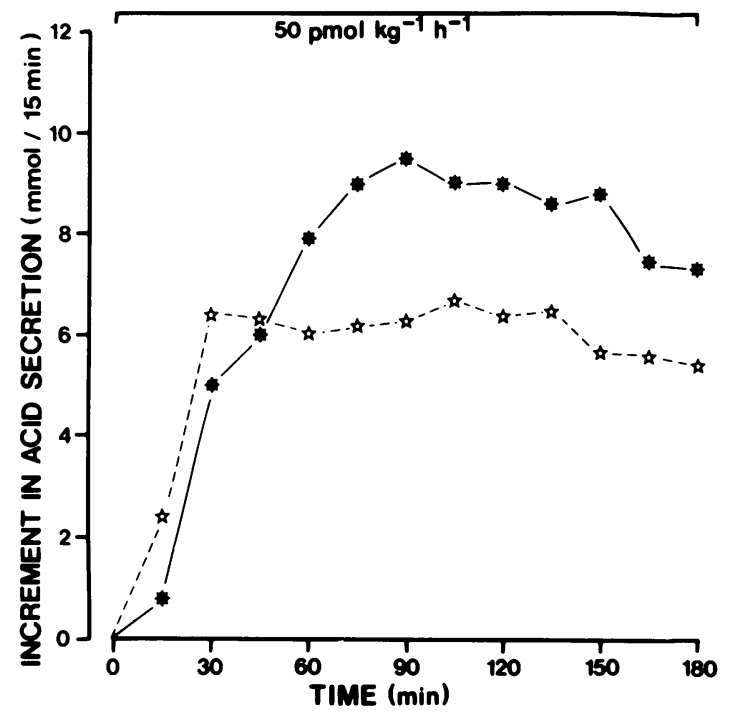

Figure 6. Increments in gastric acid secretion over basal values during 3-h intravenous infusion of G34 (solid stars) or G17 (open stars) at a dosage of $50 \mathrm{pmol} / \mathrm{kg}$ per $\mathrm{h}$ in five DU subjects.

min, mean $\pm S E)$, distribution volume $(21 \pm 2$ vs. $17 \pm 3 \%$ body $w t$, and clearance rates $(1,340$ vs. $338 \mathrm{ml} / \mathrm{min})$ were similar to those determined in the DU patients. The clearance values calculated under different conditions are summarized in Table I.

Gel filtration studies on circulating synthetic G34. Plasma samples obtained during the third hour of G34 infusion and
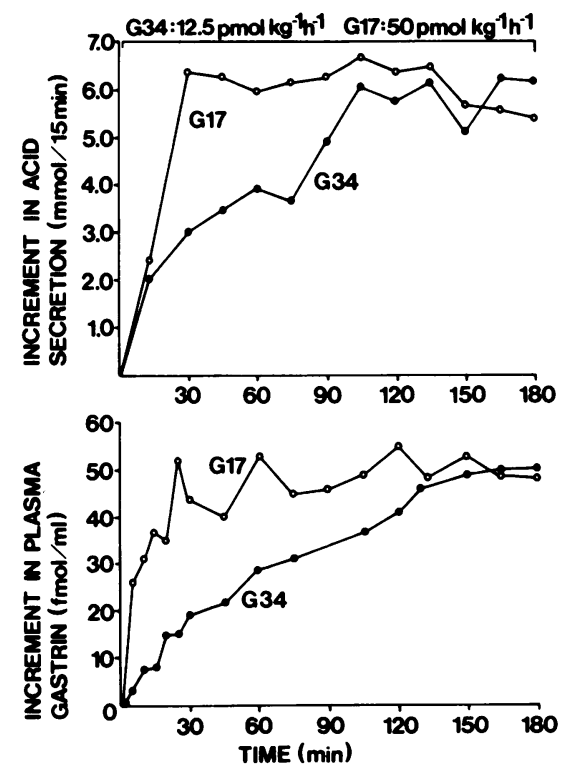

Figure 7. Increment in acid secretion (top) and in plasma gastrin (bottom) during 3-h intravenous infusion of G34 at a dosage of 12.5 $\mathrm{pmol} / \mathrm{kg}$ per $\mathrm{h}$ or $\mathrm{G} 17$ at a dosage of $50 \mathrm{pmol} / \mathrm{kg}$ per $\mathrm{h}$ in five DU subjects.

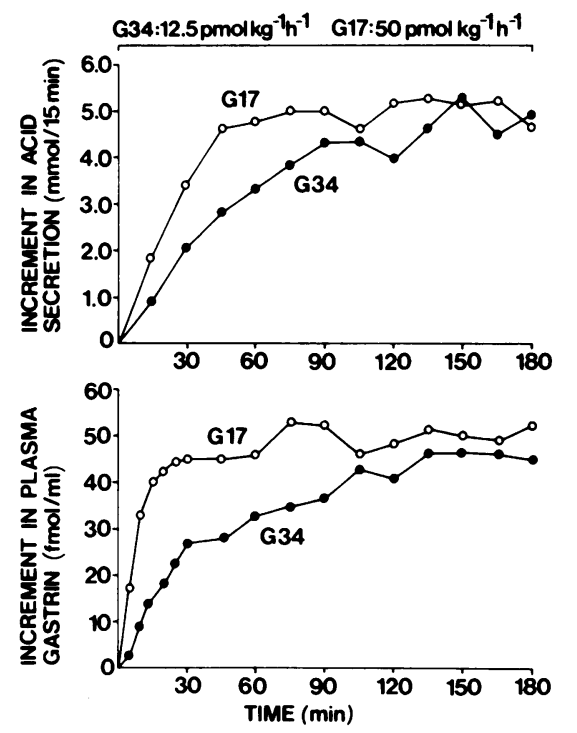

Figure 8. Increment in acid secretion (top) and in plasma gastrin (bottom) during 3-h intravenous infusion of G34 at a dosage of 12.5 $\mathrm{pmol} / \mathrm{kg}$ per $\mathrm{h}$ or $\mathrm{G} 17$ at a dosage of $50 \mathrm{pmol} / \mathrm{kg}$ per $\mathrm{h}$ in six control subjects.

subjected to gel filtration revealed an increase in immunoreactive gastrin only in the tubes that eluted from G50 superfine Sephadex in the same region as did synthetic G34 when the columns were separately calibrated. No increase was found in the G17 immunoreactive area. Under these conditions, an increase in G17 due to peripheral conversion of $>5-10 \%$ of G34 to G17 should have been detectable, but no increase was seen.

\section{Discussion}

The results obtained in DU and normal human subjects during infusions of synthetic human G34 and G17 are, with respect to half-life determinations, quite similar to earlier results from

Table I. Half-life Measurements of G34 and G17

\begin{tabular}{lll}
\hline & \multicolumn{1}{l}{$\mathrm{t}_{1 / 2}$} & \\
\cline { 2 - 3 } & $\mathrm{G} 34$ & $\mathrm{G} 17$ \\
\hline & $\min$ & $\min$ \\
Present study & & \\
$\quad$ Rapid infusion, ulcer subjects & $31 \pm 2$ & $5.2 \pm 0.7$ \\
3-h infusion, ulcer subjects & $48 \pm 6$ & $8.7 \pm 3.3$ \\
3-h infusion, normal subjects & $39 \pm 3$ & $6.9 \pm 0.6$ \\
Earlier study & & \\
$\quad$ Rapid infusion, ulcer subjects & $38 \pm 4$ & $6.4 \pm 0.8$ \\
Rapid infusion, normal subjects & - & $6.4 \pm 0.8$ \\
90-min infusion, ulcer subjects & $42 \pm 6$ & $5.2 \pm 1.3$ \\
\hline
\end{tabular}


natural human G34 and G17 but are markedly different in apparent potency of $\mathrm{G} 34$ as a stimulant of gastric acid secretion. The present study confirmed earlier findings (3) that the halflife of G34 is approximately six times longer than that of G17 in man. In that earlier study, the half-life of synthetic G17 after infusion into 11 normal and 11 DU subjects was $6.2 \mathrm{~min}$ in each group, compared with 8.7 and $6.9 \mathrm{~min}$ in the corresponding groups of six included in the present study. The half-life of G34 in the previous study, $41.5 \mathrm{~min}$, also agrees well with the values of 48 and $38.9 \mathrm{~min}$ found in the present study. These differences account for the measured four- to fivefold lower clearance rate for G34 than for G17. The higher acid-stimulating activity of G34 was a striking change from that found in the earlier study.

The simplest explanation for these differences is that there are biochemical changes in the gastrin molecule that lead to a loss of biological activity disproportionate with any loss of immunochemical reactivity with gastrin antibody. The earlier studies estimated that G34 was only about half as reactive with the antibody used for gastrin radioimmunoassay as with G17. However, the preparation of synthetic human G34 used in the present study reacted $100 \%$ as well with the antibody used in that study, 1296, as with G17. Therefore, it is reasonable to assume that the natural human gastrin preparation was either only half as pure or only half as immunoreactive as the new synthetic preparation.

The biological activity obtained with the older preparation of natural human gastrin was markedly lower than the acidstimulating activity measured with the new synthetic $G 34$, even when differences in immunochemical reactivity were taken into account. The biological responses to the new synthetic G34 are more compatible, with respect to stimulation of lower esophageal sphincter contraction in man (8), with those measured for another synthetic G34 preparation, made with a slight mistake in amino acid sequence. A relatively simple explanation, although impossible to prove because the original gastrin preparation is no longer available, is that the natural G34 became oxidized during the lengthy purification procedure. The time between initial tumor extraction and final purification and testing of the natural G34 was $\sim 2 \mathrm{yr}$, during which the peptide would have been repeatedly exposed to potential oxidizing conditions during chromatographic purification steps. Lin and co-workers (21) have shown that conversion of the methionine side-chain of gastrin tetrapeptide into one of the common products of oxidation, methionine sulfone, reduces its acid-stimulating potency by $97 \%$. Thus, oxidation of the major fraction of the old natural human G34 could account for the low biological activity measured. Similar results have been found by others who studied the structural requirements for biological activity of gastrin peptides $(22,23)$.

The conclusion of the present experiments is that G34 in the circulation represents a stimulant of acid secretion in man similar in potency and intrinsic activity to G17. These findings suggest that circulating G34 may be considerably more important in regulating human gastric secretion than previously thought
(7), and that the circulating G34 found after surgical resection of the human antrum (6) probably retains significant biological functions. These results also indicate that measurements of total circulating carboxyl-terminal gastrin immunoreactivity with an antibody specific for this region of gastrin that measures G17 and G34 equally should produce plasma gastrin values that reflect acid-stimulating activity of the circulating gastrin. Therefore, it should not be necessary to separate G17 from G34 chromatographically or by use of antibodies specific for G17 as was done previously (5) to get information. These findings may explain why a recent comparison (24) of changes in total gastrin, measured with antibody 1611 , and in G17, measured with antibody L6, during intragastric peptone infusions correlated better with acid secretory response when expressed in terms of total gastrin.

\section{Acknowledgments}

This work was supported by National Institutes of Health grants 17294 and 17328, by the Deutsche Forschungsgemeinschaft (EY 14/1-2), and by Veterans Administration Research Funds.

\section{References}

1. Gregory, R. A. 1979. A review of some recent developments in the chemistry of the gastrins. Bioorg. Chem. 8:497-511.

2. Walsh, J. H., H. T. Debas, and M. I. Grossman. 1974. Pure human big gastrin. Immunochemical properties, disappearance half time, and acid-stimulating action in dogs. J. Clin. Invest. 54:477-485.

3. Walsh, J. H., J. I. Isenberg, J. Ansfield, and V. Maxwell. 1976. Clearance and acid-stimulating action of human big and little gastrins in duodenal ulcer subjects. J. Clin. Invest. 57:1125-1131.

4. Gregory, R. A., and H. J. Tracy. 1975. The chemistry of the gastrins: some recent advances. In Gastrointestinal Hormones. J. C. Thompson, editor. University of Texas Press, Austin, TX. 13-24.

5. Taylor, I. L., G. J. Dockray, J. Calam, and R. Walker. 1979. Big and little gastrin responses to food in normal and ulcer subjects Gut. 20:957-962.

6. Lamers, C. B., J. H. Walsh, J. B. Jansen, A. R. Harrison, A. F. Ippoliti, and J. H. van Tongeren. 1982. Evidence that gastrin 34 is preferentially released from the human duodenum. Gastroenterology. 83:233-239.

7. Walsh, J. H. 1977. Gastrin heterogeneity: biological significance. Fed. Proc. 36:1948-1951.

8. Jensen, D. M., R. W. McCallum, E. Corazziari, J. Elashoff, and J. H. Walsh. 1980. Human lower esophageal sphincter responses to synthetic human gastrins 34 (G-34) and 17 (G-17). Gastroenterology. 79:431-438.

9. Dockray, G. J., C. Vaillant, and C. R. Hopkins. 1978. Biosynthetic relationships of big and little gastrins. Nature (Lond.). 274:770-772.

10. Dockray, G. J. 1980. Immunochemical studies on big gastrin using $\mathrm{NH}_{2}$-terminal specific antisera. Regul. Pept. 1:169-186.

11. Noyes, B. E., M. Mevarech, R. Stein, and K. L. Agarwal. 1979. Detection and partial sequence analysis of gastrin mRNA by using an oligodeoxynucleotide probe. Proc. Natl. Acad. Sci. USA. 76:1770-1774.

12. Boel, E., J. Vuust, F. Morris, K. Morris, A. Wind, J. F. Rehfeld, and K. I Marcker. 1983. Molecular cloning of human gastrin cDNA: 
evidence for evolution of gastrin by gene duplication. Proc. Natl. Acad. Sci. USA. 80:2866-2869.

13. Wünsch, E., G. Wendlberger, L. Mladenova-Orlinova, W. Gohring, E. Jaeger, R. Scharf, R. A. Gregory, and G. J. Dockray. 1981. Totalsynthese des Human-Big-Gastrins. I. Revidierte Primarstruktur. Hoppe-Seyler's Z. Physiol. Chem. 362:179-183.

14. Rosenquist, G. L., and J. H. Walsh. 1980. Radioimmunoassay of gastrin. In Gastrointestinal Hormones. G. B. Jerzy Glass, editor. Raven Press, New York. 769-795.

15. Walsh, J. H., C. B. Lamers, and J. E. Valenzuela. 1982. Cholecystokinin-octapeptidelike immunoreactivity in human plasma. Gastroenterology. 82:438-444.

16. Fordtran, J. S., and J. H. Walsh. 1973. Gastric acid secretion rate and buffer content of the stomach after eating. Results in normal subjects and in patients with duodenal ulcer. J. Clin. Invest. 52:645657.

17. Maxwell, V., V. E. Eysselein, J. Kleibeuker, T. Reedy, and J. H. Walsh. 1984. Glucose perfusion intragastric titration. Dig. Dis. Sci. In press.

18. Jennrich, R. 1983. P3R Nonlinear regression. In BMDP Statistical
Software. W. J. Dixon, editor. University of California Press, Berkeley. 290-304.

19. Goldstein, A., L. Aranow, and S. M. Kalman. 1968. Principles of drug action. Harper and Row, Publishers Inc., New York. 292-299.

20. Elashoff, J. D. 1981. Repeated-measures bioassay with correlated errors and heterogeneous variances: a Monte Carlo study. Biometrics, 37:475-482.

21. Lin, T.-M., G. L. Southhard, and G. F. Spray. 1976. Stimulation of gastric acid secretion in the $\operatorname{dog}$ by the $C$-terminal penta-tetra-, and tripeptides of gastrin and their $O$-methyl esters. Gastroenterology. 70:733736.

22. Tracy, H. J., and R. A. Gregory. 1964. Biological properties of a series of synthetic peptides structurally related to gastrin I. Nature (Lond.). 204:935-938.

23. Morley, J. S. 1968. Structure-function relationships in gastrinlike peptides. Proc. R. Soc. Lond. B. Biol. Sci. 170:97-111.

24. Lam, S. K., J. I. Isenberg, M. I. Grossman, W. H. Lane, and J. H. Walsh. 1980. Gastrin acid secretion is abnormally sensitive to endogenous gastrin released after peptone test in duodenal ulcer patients. J. Clin. Invest. 65:555-562. 